\title{
A statistical study of sporadic sodium layer observed by Sodium lidar at Hefei $\left(31.8^{\circ} \mathrm{N}, 117.3^{\circ} \mathbf{E}\right)$
}

\author{
X.-K. Dou ${ }^{1,2}$, X.-H. Xue ${ }^{1,2}$, T.-D. Chen ${ }^{1}$, W.-X. Wan ${ }^{3}$, X.-W. Cheng ${ }^{4}$, T. Li ${ }^{1}$, C. Chen ${ }^{1}$, S. Qiu ${ }^{1}$, and Z.-Y. Chen \\ ${ }^{1}$ School of Earth and Space Sciences, University of Science and Technology of China, Hefei, Anhui, 230026, China \\ ${ }^{2}$ Mengcheng National Geophysical Observatory, Mengcheng, China \\ ${ }^{3}$ Institute of Geology and Geophysics, Chinese Academy of Sciences, Beijing, 100029, China \\ ${ }^{4}$ Wuhan Institute of Physics and Mathematics, Chinese Academy of Sciences, Wuhan, 430071, China \\ ${ }^{5}$ Institute of Atmospheric Physics, Chinese Academy of Sciences, Beijing, 100029, China
}

Received: 22 December 2008 - Revised: 5 May 2009 - Accepted: 13 May 2009 - Published: 8 June 2009

\begin{abstract}
Sodium lidar observations of sporadic sodium layers (SSLs) during the past 3 years at a mid-latitude location (Hefei, China, $31.8^{\circ} \mathrm{N}, 117.3^{\circ} \mathrm{E}$ ) are reported in this paper. From 64 SSL events detected in about $900 \mathrm{~h}$ of observation, an SSL occurrence rate of 1 event every $14 \mathrm{~h}$ at our location was obtained. This result, combined with previous studies, reveals that the SSL occurrence can be relatively frequent at some mid-latitude locations. Statistical analysis of main parameters for the 64 SSL events was performed. By examining the corresponding data from an ionosonde, a considerable correlation was found with a Pearson coefficient of 0.66 between seasonal variations of SSL and those of sporadic E (Es) during nighttime, which was in line with the research by Nagasawa and Abo (1995). From comparison between observations from the University of Science and Technology of China (USTC) lidar and from Wuhan Institute of Physics and Mathematics (WIPM) lidar (Wuhan, China, $31^{\circ} \mathrm{N}, 114^{\circ} \mathrm{E}$ ), the minimum horizontal range for some events was estimated to be over $500 \mathrm{~km}$.
\end{abstract}

Keywords. Atmospheric composition and structure (Middle atmosphere - composition and chemistry; Pressure, density, and temperature) - Meteorology and atmospheric dynamics (Middle atmosphere dynamics)

\section{Introduction}

The deposition of extraterrestrial material in the Earth's upper atmosphere gives rise to layers of free neutral metal atoms in the altitude range from 80 to $110 \mathrm{~km}$, and a sodium

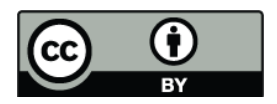

Correspondence to: X.-H. Xue

(xuexh@ustc.edu.cn) layer was first observed by a fluorescent lidar (Bowman et al., 1969). Considering the existence of various scales of atmospheric motions and the complicated photochemical reactions of elemental sodium in the mesosphere and lowerthermosphere (MLT) region, there is an inconsistency in assumptions concerning the photochemical lifetime of sodium (Gardner and Shelton, 1985; Hickey and Plane, 1995; Xu and Smith, 2003; Swider, 1986; Plane et al., 1999; Cox et al., 2001). Many researchers consider that in the interpretation of the short-time scales atmospheric dynamics (such as gravity waves and tides), the sodium layer can be regarded as a passive tracer (Gardner and Shelton, 1985; Gardner and Voelz, 1987; Kwon et al., 1987; Bills and Gardner, 1993), due to the longer lifetime of sodium atoms above $85 \mathrm{~km}$ (Xu and Smith, 2003). Extensive lidar studies of the seasonal variations of the sodium layer were conducted at different latitudes in the 1970s (Gibson and Sandford, 1971; Megie and Blamont, 1977; Simonich et al., 1979; States and Gardner, 1999; Plane et al., 1999; She et al., 2000; Gardner et al., 2005; Yi et al., 2009). With the development of narrowband lidars (Bills et al., 1991; She et al., 1992; Bills and Gardner, 1993; Papen et al., 1995), the mesospheric temperature and wind measurements has complemented sodium observations and helped to us understand the dynamical process in the MLT region.

Among the various properties of the sodium layer, the sporadic sodium layer (SSL) continues to attract the attention in recent years. The term "SSL" refers to thin layers (full width at half maximum (FWHM) $\sim 1-4 \mathrm{~km}$ ) of relatively high concentrations of $\mathrm{Na}$ atoms that appear and disappear on the topside of the normal Na layer, thus the main characteristics of SSLs are high peak density, narrow peak width, and short developing time. The first SSL observation was reported by Clemesha et al. $(1978,1980)$. More extensive

Published by Copernicus Publications on behalf of the European Geosciences Union. 
Table 1. Main specifications of USTC lidar system.

\begin{tabular}{lcc}
\hline Transmitter: & Nd:YAG & Dye Laser \\
Wavelength $(\mathrm{nm})$ & 532 & 589 \\
Pulse energy $(\mathrm{mJ})$ & 550 & 60 (typ.) \\
Line width $\left(\mathrm{cm}^{-1}\right)$ & 1 & 0.05 \\
Pulse width (ns) & 6 & 6 \\
Repetition rate $(\mathrm{Hz})$ & 20 & 20 \\
Beam divergence $(\mathrm{mrad})$ & 0.5 & 0.5 \\
Receiver-telescope: & & \\
Type & Cassegrain \\
Diameter (mm) & 1000 & \\
Field of view (mrad) & $0.2-2$ (adjustable) \\
Receiver-filter: & & \\
Wavelength (nm) & 532 & 589 \\
Bandwidth (nm) & 1.0 & 0.5 \\
Peak transmission & $\geq 60 \%$ & $70 \%$ \\
\hline
\end{tabular}

studies on SSLs by lidars were conducted after the observation by Von Zahn and Hansen (1988) (e.g. Kwon et al., 1988; Batista et al., 1989; Senft et al., 1989; Kane et al., 1991; Gardner et al., 1993; Clemesha, 1995; Clemesha et al., 1998; Qian et al., 1998; Gong et al., 2002; Clemesha et al., 2004; Williams et al., 2006, 2007; Fan et al., 2007; Nesse et al., 2008; Vishnu Prasanth et al., 2007; Yi et al., 2007; Heinrich et al., 2008).

Sporadic sodium layers have been studied for more than 20 years. Before the 1990s, SSLs were known to be common at low and high latitudes, but rare at mid-latitudes. Kwon et al. (1988) saw 16 SSLs in $30 \mathrm{~h}$ of observations at Mauna Kea $\left(19^{\circ} 50^{\prime} \mathrm{N}\right)$, and Hansen and von Zahn (1990) saw 75 SSLs in $378 \mathrm{~h}$ of measurement at Andoya $\left(69^{\circ} \mathrm{N}\right)$. At $23^{\circ} \mathrm{S}$ Batista et al. (1989) saw 65 SSLs in $3500 \mathrm{~h}$ of observations, and at Illinois $\left(40^{\circ} \mathrm{N}\right)$ Senft et al. (1989) saw only 2 SSLs in $350 \mathrm{~h}$. No SSLs were reported from mid-latitude measurements by Gibson and Sandford (1971) and Megie and Blamont (1977). But subsequent observations showed that the mid-latitude deficit was not thought to be real in recent years. For example, measurements in the Eastern Hemisphere, i.e., Tokyo $\left(35^{\circ} \mathrm{N}\right)$ from November 1991 to October 1993 and Wuhan $\left(31^{\circ} \mathrm{N}\right)$ from February 1996 to August 2001, gave a mean occurrence interval of about $10 \mathrm{~h}$ per SSL event (Nagasawa and Abo, 1995; Yi et al., 2002; Gong et al., 2002), and measurements in the Western Hemisphere, i.e., Colorado $\left(40.6^{\circ} \mathrm{N}\right)$ from April to June 2002 and June to August 2003, indicated that $65 \%$ of days and $19 \%$ of hours had SSLs (Williams et al., 2007). These observations showed much higher occurrence rates than those observed at mid-latitude before the 1990s. Williams et al. (2007) suggested that this possibly indicates a large interannual or decadal variability in the sporadic layer occurrence rate.

Recently, a Rayleigh-Sodium fluorescence lidar has been operated routinely in the campus of the Universtiy of Science and Technology of China (USTC), Hefei, China $\left(31.8^{\circ} \mathrm{N}\right.$, $\left.117.3^{\circ} \mathrm{E}\right)$ ). From December 2005 to November 2008, 64 clear-cut SSLs were observed during $900 \mathrm{~h}$ of lidar measurements. A comprehensive statistical analysis of SSL events using nearly three years of sodium density observations by USTC lidar was done, and correlations to the sporadic-E layers, together with their horizontal ranges estimated from the co-observational data obtained by two separated lidars are discussed.

\section{Instrument description and data analysis}

A Rayleigh-Sodium fluorescence lidar system was assembled, tested and deployed to the University of Science and Technology of China (USTC) at Hefei, China $\left(31.8^{\circ} \mathrm{N}\right.$, $117.3^{\circ} \mathrm{E}$ ) in December 2005 , which is used for detecting atmospheric density and temperature and sodium density (Chen et al., 2007).

In sodium resonance fluorescence operating model, the transmitter is a tunable dye laser with $60 \mathrm{~mJ}$ pulse energy and $20 \mathrm{~Hz}$ repetition rate pumped by a $\mathrm{Nd}$ :YAG laser at second harmonic wavelength $532 \mathrm{~nm}$. The dye laser is firstly tuned to the D2 resonant absorption line of sodium at $589 \mathrm{~nm}$ using a Na vapor cell, then the final fine tuning is accomplished by maximizing the signal backscattered from the sodium layer. The dye laser beam is always pointed at zenith, and the divergence of the beam is about $0.5 \mathrm{mrad}$. The backscattered photons are collected by a $1 \mathrm{~m}$ diameter Cassegrain telescope. Passing through the appropriate narrow-band interference filter, the backscattered photons are focused onto a photomultiplier tube (PMT), and then processed by a PC-based photon counting multi-channel scalar (MCS) in successive time bins. The time bin length taken here is $100 \mu$ s corresponding to a range bin length of $150 \mathrm{~m}$. The photon counts from 5000 laser shots are accumulated to attain a lidar photocount profile, the corresponding time resolution for the photocount profile series is $250 \mathrm{~s}$. The main characteristics of the USTC lidar are presented in Table 1.

Since the USTC lidar was built, we have carried on regular observation of the sodium layer at Hefei. From December 2005 to November 2008, we accumulated a total observation time of $900 \mathrm{~h}$ from 118 nights. Among these, the SSL events were selected according to the following criteria: (1) The maximum density of SSL peak must be at least two times higher than that of the background sodium layer at the same altitude, and must be more than $1000 \mathrm{~cm}^{-3}$ if the altitude of an SSL was higher than $100 \mathrm{~km}$. The background sodium density was obtained by averaging the sodium profiles during the non-sporadic period for the whole night. For some special cases, e.g. 12 August 2006, the SSL event lasted nearly for the whole night, thus the background sodium density was obtained by fitting a Gaussian to the profile at non-sporadic altitudes at the peak time. (2) The width of SSL (FWHM) must be less than $4.0 \mathrm{~km}$ (the so-called C-structure SSLs are not restricted by this criteria (Kane et al., 2001; Clemesha 


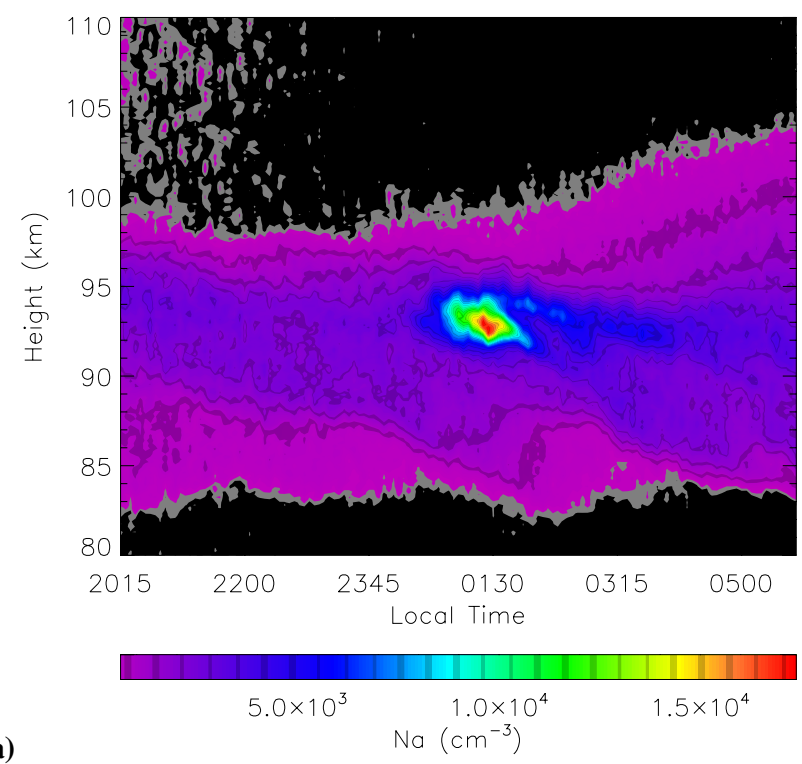

(b)
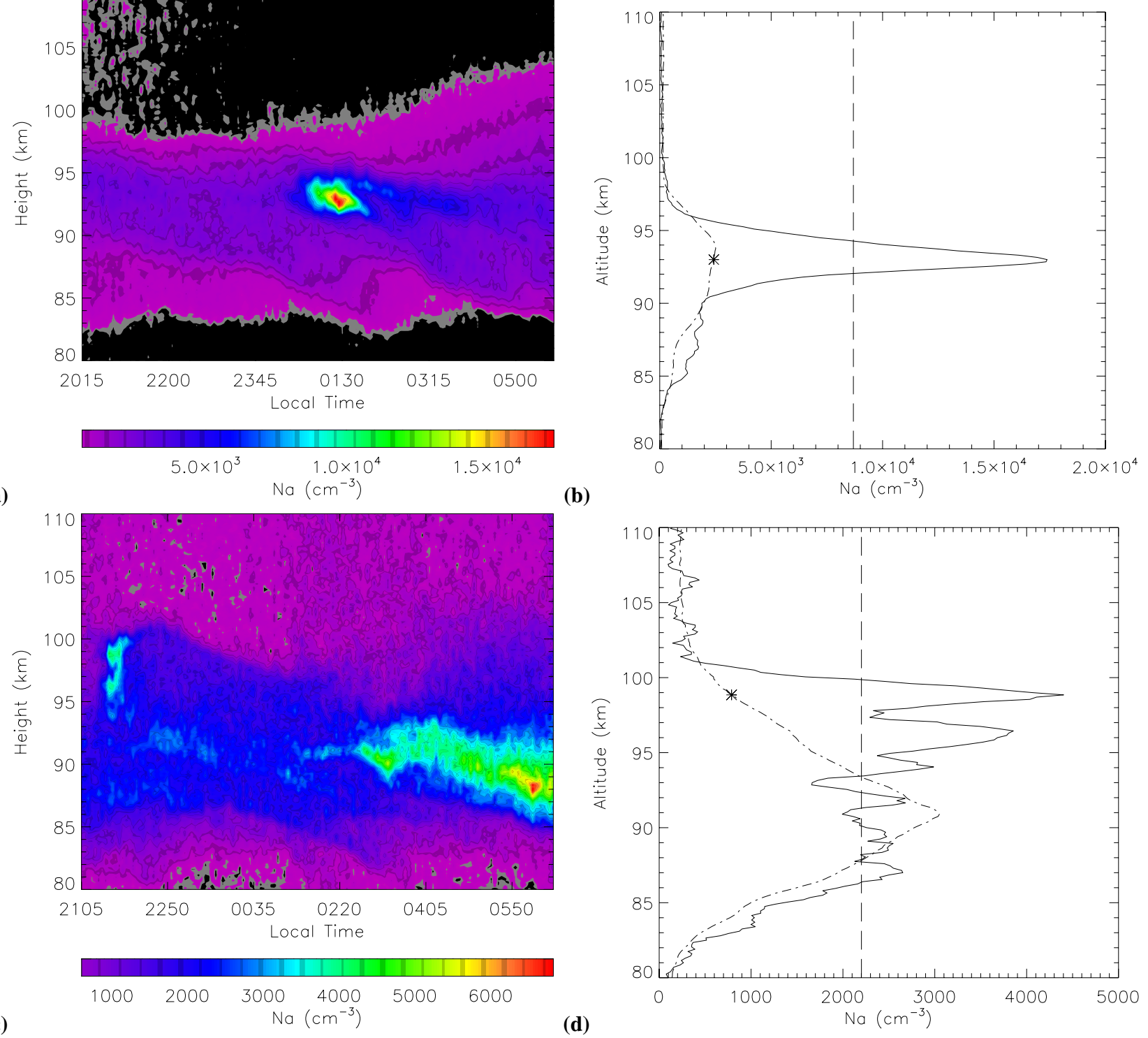

Fig. 1. Examples of the contour plots and the corresponding profiles at their maximum values of SSL events. (a-b) represent the SSL event on 20 March 2007, and (c-d) represent the SSL event on 27 January 2007. The dot-dashed lines in (b) and (d) indicate the averaged background sodium densities; the stars mark the background sodium densities corresponding to the sporadic sodium peak densities. The dashed lines show the half maximum values of the peak densities.

et al., 2004)). (3) It lasted for at least four successive lidar profiles (more than sixteen minutes). Following these conditions, 64 SSL events could be identified. More specifically, in the $900 \mathrm{~h}$ of measurements from about 118 nights, $64 \mathrm{SSL}$ events were clearly identified in 57 nights.

\section{Observations}

Figure 1 shows examples of the contour plot and the single profile plot at the moment when a sporadic sodium layer reached its maximum density on 20 March 2007 . It can be observed from Fig. 1a that a local dense sodium layer appeared during 00:12-01:53 LT on 21 March 2007. The duration of the event lasted for about $100 \mathrm{~min}$. From the profile at its maximum (Fig. 1b), one can measure its general characteristics, for example, the peak sodium density was $17380 \mathrm{~cm}^{-3}$, the relevant altitude was $93.0 \mathrm{~km}$, the full width at half maximum (FWHM) was about $2.3 \mathrm{~km}$, and the strength factor was 5.9. (The corresponding background sodium density was indicated by the dash-dot line, which was obtained from averaging the sodium density at $93.0 \mathrm{~km}$ during the non-sporadic period for the whole night.) 
Table 2. List of the SSL events during 2006-2008.

\begin{tabular}{|c|c|c|c|c|c|c|c|c|c|}
\hline Date & $\begin{array}{l}T_{0} \\
\text { (LT) }\end{array}$ & $\begin{array}{c}\Delta T_{r} \\
(\min )\end{array}$ & $\begin{array}{c}\Delta T_{f} \\
(\min )\end{array}$ & $\begin{array}{r}N_{p} \\
\left(\mathrm{~cm}^{-3}\right)\end{array}$ & $\begin{array}{r}H_{p} \\
(\mathrm{~km})\end{array}$ & $\begin{array}{r}\text { FWHM } \\
(\mathrm{km})\end{array}$ & $\mathrm{Fac}$ & $\begin{array}{r}v_{p} \\
(\mathrm{~km} / \mathrm{h})\end{array}$ & $\begin{array}{r}f_{0} E_{S} \\
(\mathrm{MHz})\end{array}$ \\
\hline \multicolumn{10}{|l|}{2006} \\
\hline $02 / 24$ & 03:05 & 25.0 & 29.0 & 5358 & 92.6 & 2.8 & 2.3 & 2.78 & 5.4 \\
\hline $03 / 14^{\dagger}$ & 01:30 & 63.0 & 125.0 & 6042 & 94.2 & 3.1 & 2.4 & -0.98 & 2.6 \\
\hline $03 / 16$ & $22: 33$ & 16.0 & 155.0 & 3843 & 95.6 & 1.5 & 3.1 & -0.60 & 2.2 \\
\hline $03 / 29$ & $20: 38$ & 17.0 & 79.0 & 4631 & 96.0 & 2.0 & 2.8 & -1.07 & 2.6 \\
\hline $03 / 30$ & 01:30 & 221.0 & $>9.0^{\mathrm{a}}$ & 4701 & 90.3 & 3.5 & 4.2 & -0.93 & 2.6 \\
\hline $06 / 02$ & $03: 37$ & 46.0 & $>8.0$ & 3642 & 93.8 & 1.2 & 6.1 & -1.45 & 13.0 \\
\hline $06 / 10$ & $02: 23$ & 16.0 & 28.0 & 2485 & 95.1 & 1.8 & 4.3 & 2.04 & 8.4 \\
\hline $06 / 17$ & $23: 23$ & 25.0 & 20.0 & 5122 & 95.6 & 1.7 & 7.6 & 1.07 & 8.2 \\
\hline $06 / 20$ & 01:27 & 91.0 & 25.0 & 1780 & 102.0 & 3.6 & 3.9 & 0.20 & 4.8 \\
\hline $06 / 20$ & $21: 42$ & 167.0 & 126.0 & 5739 & 94.7 & 4.0 & 2.3 & -0.79 & 4.8 \\
\hline $07 / 12$ & $23: 21$ & 100.0 & 96.0 & 4222 & 95.9 & 4.7 & 4.6 & 0.65 & 5.9 \\
\hline $07 / 13$ & $21: 35$ & 34.0 & 42.0 & 6143 & 95.6 & 2.9 & 8.1 & 0.10 & 8.5 \\
\hline $07 / 14^{*}$ & 01:42 & 12.0 & 75.0 & 5267 & 93.5 & 3.2 & 6.4 & -2.12 & 8.5 \\
\hline 08/09 & $21: 17$ & 97.0 & 25.0 & 6841 & 94.2 & 3.0 & 9.9 & -1.43 & 8.4 \\
\hline $08 / 12$ & $00: 13$ & 21.0 & 46.0 & 4263 & 95.4 & 3.5 & 3.1 & 1.14 & 8.0 \\
\hline $08 / 18$ & 20:03 & 16.0 & 149.0 & 11065 & 97.4 & 1.1 & 10.5 & 0.72 & 7.4 \\
\hline $09 / 06^{\dagger}$ & $21: 17$ & 16.0 & 50.0 & 4781 & 93.6 & 2.6 & 4.9 & 1.65 & 3.2 \\
\hline $10 / 15$ & $22: 07$ & 25.0 & 25.0 & 2151 & 100.8 & 2.8 & 3.7 & -0.55 & 5.2 \\
\hline $10 / 23$ & $19: 39$ & 18.0 & 96.0 & 4646 & 98.1 & 2.8 & 4.9 & 0.83 & 4.0 \\
\hline $11 / 12^{\dagger}$ & $03: 34$ & 50.0 & 46.0 & 4087 & 88.8 & 1.9 & 3.6 & -0.06 & 2.6 \\
\hline $11 / 30$ & $21: 20$ & 21.0 & 96.0 & 2772 & 92.9 & 2.6 & 2.1 & -0.63 & 3.0 \\
\hline $12 / 01^{*}$ & 19:00 & 34.0 & 33.0 & 2482 & 103.4 & 3.9 & 13.5 & -3.10 & 4.2 \\
\hline $12 / 14^{\dagger}$ & $23: 00$ & 20.0 & 102.0 & 5511 & 93.2 & 2.7 & 3.6 & -0.45 & 4.0 \\
\hline $12 / 17$ & 01:21 & 21.0 & 146.0 & 5692 & 93.3 & 3.1 & 2.9 & 0.87 & 7.4 \\
\hline $12 / 17$ & $22: 45$ & 113.0 & 110.0 & 8799 & 90.5 & 3.2 & 7.7 & -0.25 & 3.3 \\
\hline $12 / 20$ & 23:00 & 46.0 & 17.0 & 4998 & 94.5 & 2.2 & 2.3 & -1.99 & 3.3 \\
\hline $12 / 29$ & $19: 47$ & 33.0 & $>34.0$ & 5888 & 95.3 & 2.7 & 2.7 & -0.13 & 2.7 \\
\hline \multicolumn{10}{|l|}{2007} \\
\hline $01 / 06^{\dagger}$ & $21: 11$ & 255.0 & 100.0 & 8311 & 92.7 & 3.9 & 3.4 & -0.48 & 9.1 \\
\hline $01 / 27^{*}$ & $21: 33$ & 8.0 & 29.0 & 4403 & 98.9 & 6.4 & 5.6 & 0.30 & 3.5 \\
\hline $01 / 28$ & $22: 49$ & 92.0 & 96.0 & 3200 & 96.9 & 2.4 & 3.5 & -0.50 & 2.0 \\
\hline $01 / 31$ & $19: 26$ & 57.0 & 50.0 & 6339 & 92.4 & 2.8 & 2.0 & -0.49 & 1.7 \\
\hline $02 / 03$ & 00:08 & 12.0 & 29.0 & 8107 & 95.0 & 3.8 & 5.3 & 0.50 & 3.0 \\
\hline $02 / 03^{*}$ & $00: 50$ & 29.0 & 21.0 & 11234 & 93.0 & 3.9 & 5.6 & 0.89 & 3.0 \\
\hline $03 / 21^{\dagger}$ & $00: 12$ & 67.0 & 34.0 & 17380 & 93.0 & 2.3 & 5.9 & -0.65 & 2.4 \\
\hline $03 / 27$ & $22: 22$ & 25.0 & 8.0 & 8772 & 94.1 & 1.9 & 3.6 & 0.13 & 2.4 \\
\hline $03 / 30$ & $00: 18$ & 75.0 & $>104.0$ & 12410 & 92.3 & 2.3 & 4.9 & -1.85 & 5.9 \\
\hline
\end{tabular}

The typical parameters of all 64 SSL events of USTC lidar observation, i.e., the beginning time of a SSL $\left(T_{0}\right)$, the rising time $\left(\Delta T_{r}\right.$, defined as the time elapsed between the first appearance of a SSL and its reaching maximum amplitude), the falling time $\left(\Delta T_{f}\right.$, defined as the time elapsed between the maximum amplitude to the last profile where the peak is still distinguishable), the maximum peak density of a SSL $\left(N_{p}\right)$, the corresponding altitude of the maximum peak density $\left(H_{p}\right)$, the width (FWHM), and the strength factor (Fac), are listed in the second to eighth columns of Table 2.
Figure 2 gives a statistical analysis of some main parameters for all of the 64 SSL events. From Fig. 2a, most of the SSL events were located at the altitude range of 90-104 km, with an average altitude of $94.8 \mathrm{~km}$. This result is consistent with previous observations at low- and mid-latitudes (e.g. Batista et al., 1989; Vishnu Prasanth et al., 2007; Gong et al., 2002). It was also similar to that seen at high-latitude (i.e., Andoya) by Hansen and von Zahn (1990), except that in winter, a considerable number of SSLs were seen at greater heights, between 100 and $110 \mathrm{~km}$. 
Table 2. Continued.

\begin{tabular}{|c|c|c|c|c|c|c|c|c|c|}
\hline Date & $\begin{array}{l}T_{0} \\
\text { (LT) }\end{array}$ & $\begin{array}{c}\Delta T_{r} \\
(\min )\end{array}$ & $\begin{array}{c}\Delta T_{f} \\
(\min )\end{array}$ & $\begin{array}{r}N_{p} \\
\left(\mathrm{~cm}^{-3}\right)\end{array}$ & $\begin{array}{r}H_{p} \\
(\mathrm{~km})\end{array}$ & $\begin{array}{r}\text { FWHM } \\
(\mathrm{km})\end{array}$ & $\mathrm{Fac}$ & $\begin{array}{r}v_{p} \\
(\mathrm{~km} / \mathrm{h})\end{array}$ & $\begin{array}{r}f_{0} E_{s} \\
(\mathrm{MHz})\end{array}$ \\
\hline 04/11* & $02: 50$ & 25.0 & $>30.0$ & 3207 & 95.1 & 3.8 & 4.0 & 1.44 & 8.6 \\
\hline $05 / 19 *$ & 02:29 & 54.0 & 33.0 & 10835 & 94.5 & 2.9 & 16.4 & 0.81 & 10.6 \\
\hline 06/08 & 01:10 & 38.0 & 146.0 & 10402 & 93.3 & 1.6 & 11.2 & -1.04 & 16.3 \\
\hline $07 / 27$ & $22: 29$ & 100.0 & 250.0 & 5845 & 93.8 & 2.4 & 2.4 & -0.83 & 7.9 \\
\hline 08/08 & $22: 06$ & $>67.0^{\mathrm{b}}$ & 100.0 & 8654 & 95.7 & 1.7 & 5.5 & -0.64 & 5.4 \\
\hline $08 / 12$ & $21: 55$ & 134.0 & 279.0 & 3935 & 95.6 & 2.9 & 2.8 & -0.91 & 7.3 \\
\hline $08 / 18$ & $02: 34$ & 79.0 & $>25.0$ & 4278 & 94.8 & 2.9 & 2.8 & -2.20 & 7.6 \\
\hline $11 / 02^{\dagger}$ & $22: 24$ & 33.0 & 29.0 & 10720 & 92.4 & 3.9 & 2.5 & -0.46 & 4.4 \\
\hline $11 / 03^{\dagger}$ & 01:36 & 121.0 & 71.0 & 17242 & 92.1 & 1.5 & 4.1 & 0.24 & 4.4 \\
\hline $11 / 18$ & $22: 50$ & 171.0 & 130.0 & 7339 & 90.2 & 1.7 & 3.6 & -1.40 & 2.4 \\
\hline $12 / 14^{\dagger}$ & $05: 44$ & 25.0 & $>4.0$ & 10593 & 88.5 & 1.5 & 4.4 & -0.34 & 1.9 \\
\hline $12 / 14$ & $23: 16$ & 29.0 & $>16.0$ & 5947 & 95.7 & 3.3 & 2.4 & -0.38 & 3.9 \\
\hline $12 / 19$ & $22: 48$ & 63.0 & 133.0 & 7688 & 94.2 & 2.6 & 4.1 & -2.22 & 2.4 \\
\hline $12 / 20$ & 01:02 & 58.0 & 42.0 & 4814 & 96.0 & 1.9 & 2.2 & 0.80 & 2.4 \\
\hline $12 / 30^{\dagger}$ & $00: 23$ & 12.0 & 21.0 & 6164 & 92.7 & 1.5 & 2.7 & 0.33 & 5.5 \\
\hline \multicolumn{10}{|l|}{2008} \\
\hline $02 / 28$ & 01:37 & 63.0 & 125.0 & 9130 & 93.3 & 3.3 & 3.8 & -1.68 & 3.6 \\
\hline $02 / 29$ & 20:06 & 125.0 & 129.0 & 8737 & 93.5 & 3.4 & 3.2 & -0.70 & 8.1 \\
\hline $03 / 10$ & $21: 46$ & 146.0 & 309.0 & 6371 & 95.0 & 2.9 & 3.7 & -0.38 & 1.9 \\
\hline $03 / 14$ & $23: 21$ & 38.0 & 21.0 & 4784 & 95.3 & 1.9 & 3.1 & -0.44 & 6.4 \\
\hline $03 / 15$ & $01: 22$ & 13.0 & 46.0 & 6563 & 93.8 & 1.4 & 4.2 & 0.52 & 6.5 \\
\hline $03 / 26$ & $02: 54$ & 33.0 & 58.0 & 3866 & 95.9 & 2.1 & 4.5 & 0.32 & 2.3 \\
\hline $04 / 29$ & $00: 42$ & 8.0 & 21.0 & 1319 & 103.7 & 1.2 & 8.9 & 0.88 & $-^{\mathrm{c}}$ \\
\hline $05 / 13$ & $02: 36$ & 113.0 & $>4.0$ & 3837 & 96.0 & 4.0 & 2.6 & -0.57 & - \\
\hline $05 / 20$ & 02:12 & 33.0 & 121.0 & 7297 & 95.4 & 2.9 & 22.8 & -0.44 & - \\
\hline 08/06 & $22: 33$ & 17.0 & 33.0 & 3100 & 93.6 & 3.1 & 2.5 & -1.09 & - \\
\hline 09/01 & $21: 48$ & 108.0 & 121.0 & 5715 & 90.8 & 3.4 & 2.9 & -0.50 & - \\
\hline $10 / 23$ & $20: 46$ & 42.0 & 17.0 & 1378 & 100.5 & 1.4 & 3.0 & 0.15 & - \\
\hline $10 / 24$ & 01:13 & 17.0 & 25.0 & 1716 & 101.3 & 1.5 & 4.6 & 1.01 & - \\
\hline
\end{tabular}

${ }^{a}$ Lidar did not observe the end of SSL event

$\mathrm{b}$ Lidar did not observe the beginning of SSL event

${ }^{\mathrm{c}}$ No corresponding data set

* C-structure SSL event

$\dagger$ Wuhan Lidar had the corresponding observational data

Figure $2 \mathrm{~b}$ shows the distribution of the width of the 64 SSL events, which was around $1.0-4.0 \mathrm{~km}$ for most of the normal SSL events and had an average value of $2.6 \mathrm{~km}$. One exception was the case on 27 January 2007 as shown in Fig. 1cd. One can find in Fig. 1c, that a structure like a reversed letter "C" appeared during 21:33 LT-22:10 LT between 95$100 \mathrm{~km}$, the width of this event was about $6.4 \mathrm{~km}$ (shown in Fig. 1d), the maximum width among all the SSL events. The so-called C-structure SSL event was first observed by Kane et al. (2001), and named by Clemesha et al. (2004). Actually, we observed six C-structure SSL events (indicated by stars in Table 2): one was a reversed C-structure SSL, the other five were normal C-structure one. Because C-structure SSLs often showed complex height/time structures, extend- ing over several kilometers in height and around $1 \mathrm{~h}$ in time, the width of them was wider than that of the normal SSL events. As to the six cases mentioned above, the average width was $4.0 \mathrm{~km}$, with minimum value of $2.9 \mathrm{~km}$ and maximum value of $6.4 \mathrm{~km}$. This value was much wider than that of the averaged normal SSL $(2.6 \mathrm{~km})$. Regarding the formation of these structures, Clemesha et al. (2004) suggested that they could be caused by a wind-shear distortion of an initial cloud of enhanced sodium concentration having certain fixed horizontal dimensions and extending over a height range of up to $10 \mathrm{~km}$. Moreover, whether the reversed C-structure (as shown Fig. 1c) was caused by the same manifestation is questionable, and further observations of the dynamical parameters (e.g., wind field, temperature) are needed. 

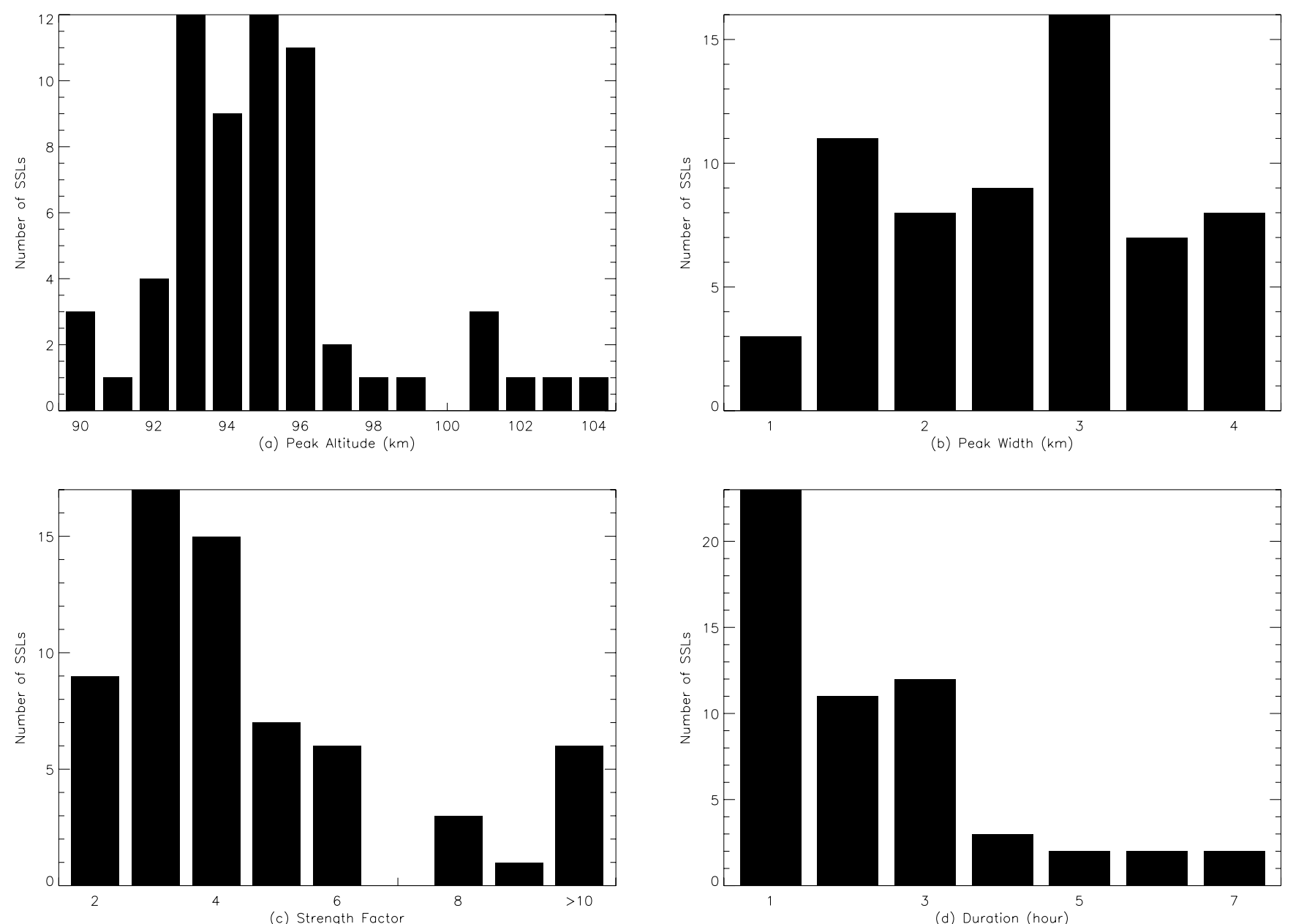

Fig. 2. Statistical plots of peak altitudes, width (FWHM), strength factors and durations for SSL events.

The strength factors of most SSL events were distributed within the range 2-6 as shown in Fig. 2c, with a relatively high value $>10$ for six events. In particular, the SSL event on 20 May 2008 had a strength factor of 22.8 , due to the relatively lower sodium density above $95 \mathrm{~km}$ during nonsporadic period (average value $\sim 400 \mathrm{~cm}^{-3}$ ).

Figure $2 \mathrm{~d}$ gives the distribution of the durations of the SSL events. This statistical plot excluded those events for which we did not observe the beginning times or ending times. One can find that most of them lasted for about $1-3 \mathrm{~h}$. These results agree with those reported by other sodium lidar groups (Batista et al., 1989; Yi et al., 2002; Gong et al., 2002; Vishnu Prasanth et al., 2007). Figure 3 shows the histogram distribution of the ratio of the falling times versus rising times for the SSL events analyzed in Fig. 2d, and it indicates that the falling times were a little longer than the rising times. The rising times ranged from $8 \mathrm{~min}$ to over $4 \mathrm{~h}$ with an average of $56 \mathrm{~min}$, and the falling times ranged from $8 \mathrm{~min}$ to over $5 \mathrm{~h}$ with an average of $79 \mathrm{~min}$. These values were in line with those observed at $23^{\circ} \mathrm{S}$ (i.e., Batista et al., 1989, showed the average rising times and falling times of SSLs were $50 \mathrm{~min}$ and $174 \mathrm{~min}$, respectively), but were generally longer than those seen at low latitude (i.e., Kwon et al., 1988, observed fifty percent of the SSLs had apparent rising times of less than $10 \mathrm{~min}$, and about $2 / 3$ of the falling times were greater than $10 \mathrm{~min}$, with $1 / 3$ greater than $20 \mathrm{~min}$ ) and high latitude (i.e., von Zahn et al., 1987, illustrated that the SSLs increased by large factors within a few minutes). Most of observations proved that the rising times were shorter than falling times, but Vishnu Prasanth et al. (2007) have seen longer rising times of about $48 \mathrm{~min}$ on an average and shorter falling times with an average of $30 \mathrm{~min}$.

Figure 4 illustrates another time characteristics of SSLs, i.e., occurrence of SSLs versus local time, which was obtained from dividing the numbers of the SSLs by the total observational time during a certain local time interval. As can be seen from this figure, the events can occur at any time during the whole observational nights, but they showed 


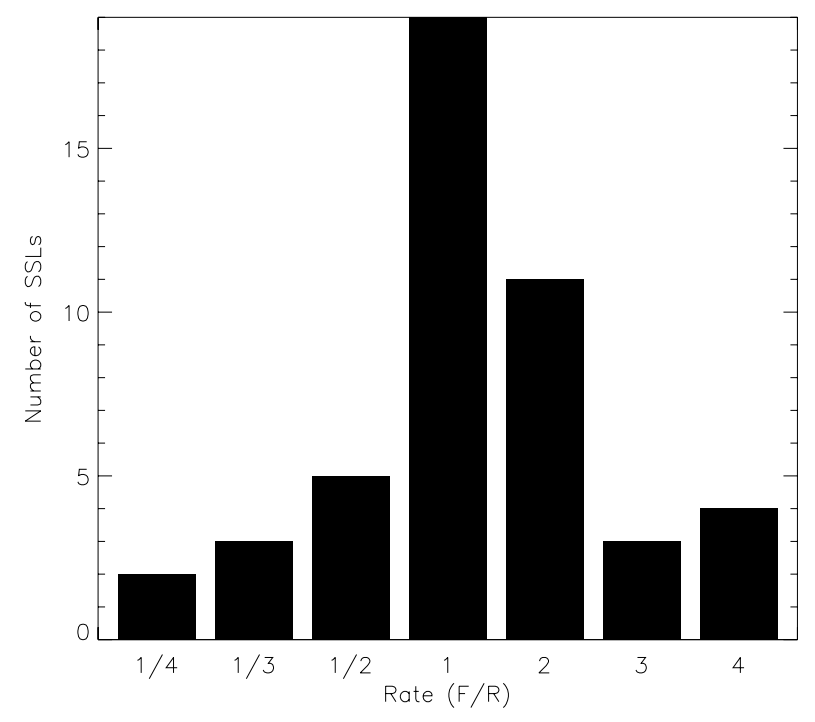

Fig. 3. Statistical plot of the Rate of Falling time (F) to Rising time (R).

more frequent occurrence near midnight. Previous studies showed that the occurrence was concentrated near midnight for high-latitude SSLs (Hansen and von Zahn, 1990; Heinrich et al., 2008), but had a relatively wide distribution versus local time for low- and mid-latitude SSLs (Batista et al., 1989; Clemesha, 1995; Vishnu Prasanth et al., 2007; Gong et al., 2002). This was also true from our observations. It is worth mentioning that observations at night with limited operation hours can not reveal the whole local-time dependence of SSLs, thus the specific timing of dataset and analyzing all the sodium datasets in the same fashion must be accounted for in order to understand the variations of SSLs better.

Another statistical parameter is the velocity of the trajectories of the sporadic sodium peak as shown in the 9th column of Table 2 and Fig. 5, which was obtained by linear fitting of the height-time relation for SSL peaks on a given night. The positive and negative velocities represent the upward and downward motions of SSL peaks, respectively. The velocities were considered as zero if they are between $\pm 0.5 \mathrm{~km} / \mathrm{h}$. In this situation, we deemed the sporadic layer to be "stable". For all these 64 SSL events, 22 events were "stable" versus time, 25 events showed downward motions with average velocities $-1.25 \mathrm{~km} / \mathrm{h}$, and 17 events showed upward motions with average velocities near $1.08 \mathrm{~km} / \mathrm{h}$. Batista et al. (1989) found most SSLs showed downward motion with a rate of $1 \mathrm{~km} / \mathrm{h}$ at $23^{\circ} \mathrm{S}$. The observations of Kwon et al. (1988) at Mauna Kea showed a typical rate of descent about twice of that observed by Batista et al., and Vishnu Prasanth et al. (2007) also reported a downward motion with a velocity $2 \mathrm{~km} / \mathrm{h}$. At the same time, Gong et al. (2002) supported the results observed by Batista et al. (1989), and according to their observations at Wuhan, downward motions occurred

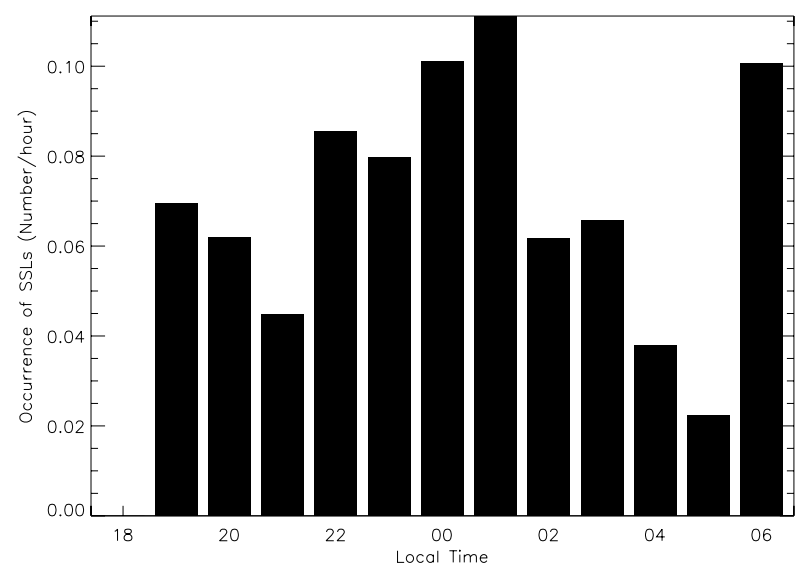

Fig. 4. Statistical plot of the SSL occurrence time.

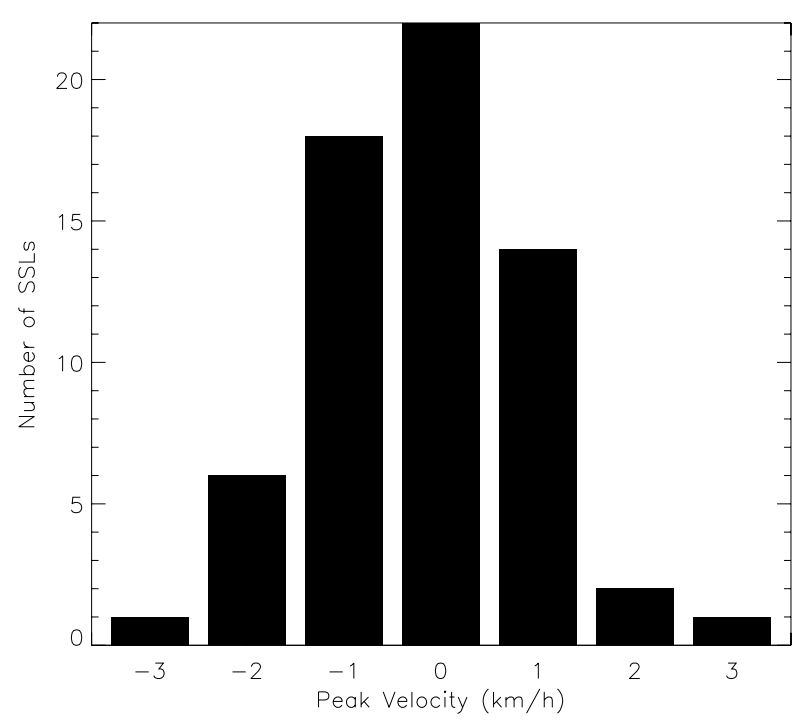

Fig. 5. Statistical plot of the average velocity of the SSL peaks trajectories. Positive and negative values represent the upward and downward motions of SSL peaks, respectively.

more often than upward ones (about 4 times more). These results were a little different from our lidar observations, which shows that SSLs are perturbed by local dynamics processes of the atmosphere during their development.

\section{Discussion and conclusions}

From our observations during December 2005 to November 2008, in nearly $900 \mathrm{~h}$ measurements over 118 nights, 64 SSL events were clearly identified in 57 nights, and the occurrence interval of $14.1 \mathrm{~h}$ per SSL event was a little lower than that observed at Wuhan, Tokyo, and Colorado. 

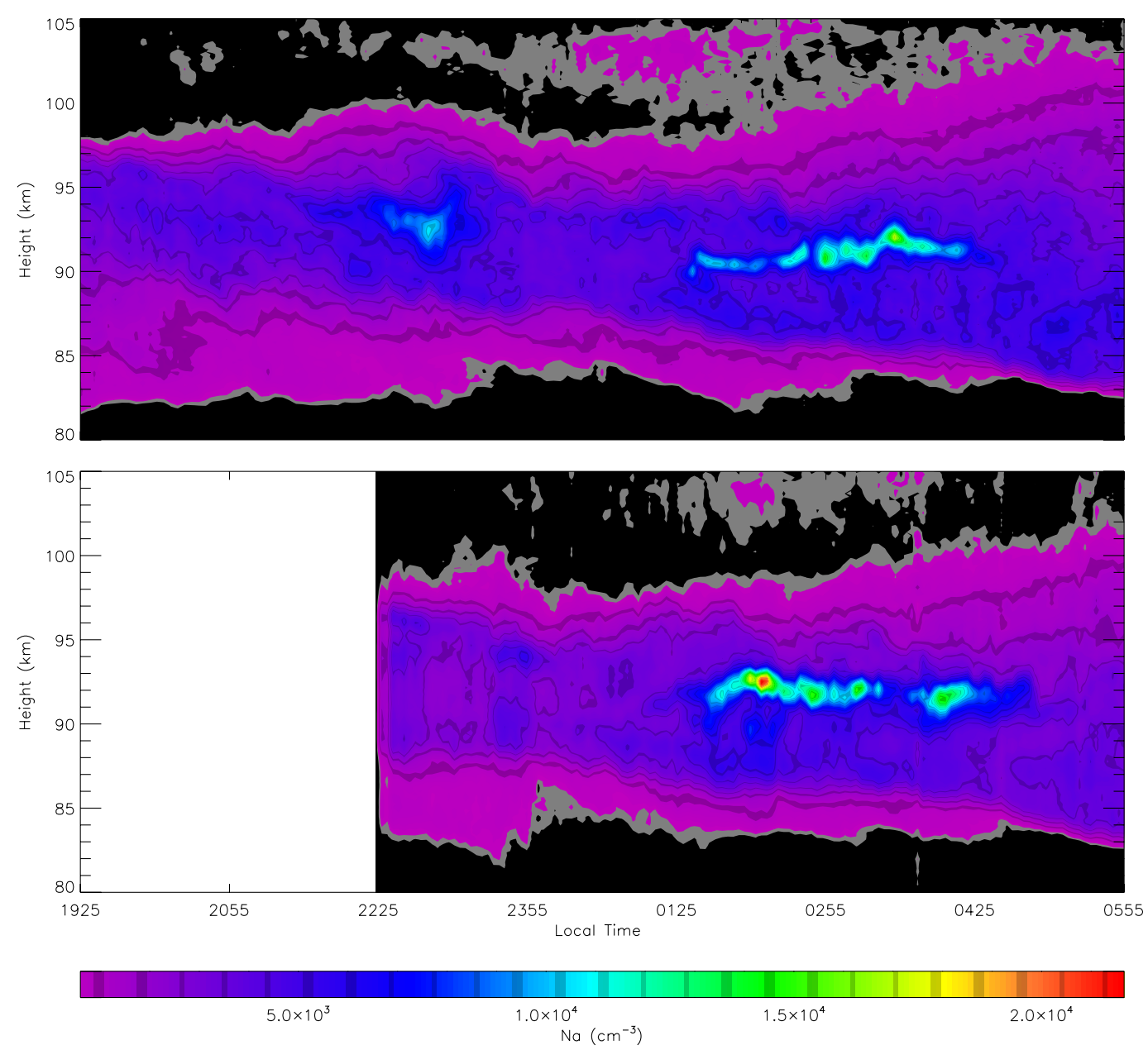

Fig. 6. Co-observation of USTC lidar (upper panel) and WIPM lidar (bottom panel) for an SSL event on 2 November 2007 at Hefei and Wuhan.

Table 3. Seasonal variations of probability of occurrence of SSL and $E_{S}$.

\begin{tabular}{lcccc}
\hline Month & $\begin{array}{c}\text { Total Obs. } \\
\text { (Hour) }\end{array}$ & $\begin{array}{c}\text { SSL No. } \\
\text { (Hour) }\end{array}$ & $\begin{array}{c}\text { SSL Occurrence } \\
\text { (Hour per SSL) }\end{array}$ & $\begin{array}{c}f_{0} E_{S}>5 \mathrm{MHz} \\
(\%)\end{array}$ \\
\hline Jan & 69.9 & 4 & 17.5 & 3.39 \\
Feb & 46.9 & 5 & 9.4 & 3.32 \\
Mar & 117.8 & 11 & 10.7 & 1.65 \\
Apr & 44.4 & 2 & 22.2 & 5.92 \\
May & 43.8 & 3 & 14.6 & 31.84 \\
Jun & 38.6 & 6 & 6.4 & 36.20 \\
Jul & 21.0 & 4 & 5.2 & 28.86 \\
Aug & 76.3 & 7 & 10.9 & 22.75 \\
Sep & 24.7 & 2 & 12.3 & 5.42 \\
Oct & 82.1 & 4 & 20.5 & 4.28 \\
Nov & 166.0 & 5 & 33.2 & 0.91 \\
Dec & 168.0 & 11 & 15.3 & 2.52 \\
Total & 899.4 & 64 & 14.1 & 12.26 \\
\hline
\end{tabular}

Seasonal variations of occurrence of SSL events are listed in 4th column in Table 3, which were obtained from dividing the total observational time of a given month (2nd column in Table 3) by the numbers of the SSL events (3rd column in Table 3). One can infer that SSL had a high frequency about 1 event per $6 \mathrm{~h}$ during summer months, especially in June and July, and a lowest frequency (1 event every $33.2 \mathrm{~h}$ ) during November.

The current theory for the formation of sporadic sodium layers is that sodium ions in a metallic ion sporadic-E (Es) layer are concentrated by wind shears interacting with the electrodynamics, which is then pushed downwards with the downward phase propagation of most waves and tides (Cox and Plane, 1998; Collins et al., 2002). From the earliest observations of SSLs, there was a strong evidence of a relationship with sporadic-E (Es). A correlation between the occurrence of SSL and Es was first noted by Clemesha et al. (1980) and has subsequently been confirmed by many studies (Von Zahn and Hansen, 1988; Mathews et al., 1993; 
Table 4. Parameters of five co-observational SSL events observed at Wuhan by WIPM lidar.

\begin{tabular}{lrrrrrrrc}
\hline Date & $\begin{array}{r}T_{0} \\
(\mathrm{LT})\end{array}$ & $\begin{array}{r}\Delta T_{r} \\
(\mathrm{~min})\end{array}$ & $\begin{array}{c}\Delta T_{f} \\
(\mathrm{~min})\end{array}$ & $\begin{array}{c}N_{p} \\
\left(\mathrm{~cm}^{-3}\right)\end{array}$ & $\begin{array}{c}H_{p} \\
(\mathrm{~km})\end{array}$ & $\begin{array}{c}\text { FWHM } \\
(\mathrm{km})\end{array}$ & Fac & $\begin{array}{c}v_{p} \\
(\mathrm{~km} / \mathrm{h})\end{array}$ \\
\hline 14 Mar 2006 & $<01: 34$ & $>33.0$ & $>9.0$ & 8164 & 94.1 & 4.3 & 3.1 & 0.43 \\
15 Dec 2006 & $<00: 40$ & $>33.0$ & $>39.0$ & 3074 & 92.4 & 3.3 & 3.3 & -0.47 \\
15 Dec 2006 & $<04: 13$ & $>0.0$ & $>39.0$ & 6509 & 90.8 & 2.9 & 3.9 & -1.15 \\
6 Jan 2007 & $<21: 56$ & $>282.0$ & $<81.0$ & 5641 & 95.2 & 1.9 & 2.0 & 0.66 \\
3 Nov 2007 & $01: 37$ & 27.0 .0 & 165.0 & 21664 & 92.5 & 1.5 & 5.6 & -0.25 \\
14 Dec 2007 & $05: 14$ & 42.0 .0 & $>0.0$ & 12622 & 89.3 & 2.8 & 4.4 & 0.77 \\
\hline
\end{tabular}

Nagasawa and Abo, 1995). Recognition of the relationship between SSL and Es events may prove to be an important additional clue regarding the origins of both layering processes. In order to study the correlation between SSL and Es during our observational period, we employed the corresponding $f_{0} E_{s}$ data from an ionosonde at Yamagawa $\left(31.2^{\circ} \mathrm{N}\right.$, $130.5^{\circ} \mathrm{E}$ ) from January 2006 to March 2008 . The maximum values of $f_{0} E_{s}$ at the corresponding night of SSL events are listed in the last column of Table 2. Due to the long horizontal distance between Hefei and Yamagawa $(\sim 1000 \mathrm{~km})$, the statistical analysis will be more illustrative. We counted the occurrence of $f_{0} E_{s}>5 \mathrm{MHz}$ from sunset to sunrise of every month at Yamagawa; the results are listed in the last column of Table 3. One can see the considerable correlation between seasonal variations of occurrence of SSL and those of Es during nighttime. The linear Pearson correlation coefficient between the inverse of SSL occurrences in Table 3 (i.e., the numbers of SSL events per hour) and the occurrences of $f_{0} E_{s}>5 \mathrm{MHz}$ is 0.66 .

Up to now, there have been few published results concerning the horizontal ranges of SSLs. One exception was a study of $19 \mathrm{SSLs}$ at $23^{\circ} \mathrm{S}$ using a steerable lidar (Batista et al., 1991), where the horizontal dimensions of the $\mathrm{Na}$ clouds were found to be between 100 and $2000 \mathrm{~km}$. An airborne lidar (ALOHA90) has also been used to show that an SSL in the Pacific equatorial region extended for more than $1800 \mathrm{~km}$ (Kane et al., 1991). Another airborne observation (ALOHA/ANLC-93) showed that the horizontal extents varied from approximately 25 to almost $1600 \mathrm{~km}$ with a mean of $440 \mathrm{~km}$ (Qian et al., 1998). Recently, satelliteborne measurements illustrated that most SSLs were much more prevalent in the Southern Hemisphere, with a horizontal extent of less than $300 \mathrm{~km}$ (Fan et al., 2007). The Wuhan Institute of Physics and Mathematics (WIPM) built the first sodium lidar system in China in 1996 (Gong et al., 2002), which is located at Wuhan $\left(31^{\circ} \mathrm{N}, 114^{\circ} \mathrm{E}\right)$ about $500 \mathrm{~km}$ away from Hefei. In suitable weather conditions, the WIPM lidar and the USTC lidar can provide latitude horizontal coobservation of sodium layer.

Figure 6 shows an SSL event observed on 2 November 2007 by the USTC lidar and the WIPM lidar together. The corresponding observational time interval for the USTC li- dar and the WIPM lidar were 19:25-05:55 LT and 22:2505:55 LT. There were two SSL events detected by the USTC lidar, one developed from 22:24-23:26 LT and the other from 01:36 LT-04:48 LT. However, the first SSL event was not detected by the WIPM lidar, and only the last one was observed by the WIPM lidar from 01:37-04:49 LT. The duration, appearance altitude, and strength of this SSL event were very consistent with those of observed by the USTC lidar.

We checked the WIPM lidar observational data, and for the 57 nights listed in Table 2, there were a total of nine nights (indicated by " $\dagger$ " in Table 2) on which the WIPM lidar had co-observational data. But for the days, i.e., 6 September 2006, 20 March 2007, and 29 December 2007, the observations of the WIPM lidar did not cover the periods of SSL developments (the corresponding observational periods of the WIPM lidar were 23:40-00:01 LT on 6 September 2006, 02:14-03:17 LT on 20 March 2007, 18:36-19:18 LT and 04:24-05:18 LT on 29 December 2007). Also, for 12 November 2006, the observations of the WIPM lidar (from 00:20-03:50 LT) just covered the beginning time of SSL observed by the USTC lidar and no evident SSL event had been observed. Thus, these four days were excluded and only five days were used here.

The typical parameters of SSL events observed by the WIPM lidar, that is, the beginning time $\left(T_{0}\right)$, the rising time $\left(\Delta T_{r}\right)$, the falling time $\left(\Delta T_{f}\right)$, the maximum peak density $\left(N_{p}\right)$, the altitude of the maximum peak density $\left(H_{p}\right)$, width (FWHM), and the strength factor (Fac), are listed in Table 4. Since the observational period only covered some time intervals instead of the whole night, the WIPM lidar did not detect the whole process of the SSL developments for some events listed in Table 4 (" $<$ " indicated that the beginning time was not observed, and "> " indicates that the corresponding periods were longer than those shown in Table 4).

One can find from comparing Table 4 with Table 2 that the SSL events for these five nights listed in Table 2 (except one from 22:24-23:26 LT on 2 November 2007) were observed by the WIPM lidar simultaneously, and the durations, peak altitudes, widths and strength for the same events at the two locations were very close. This indicates that these SSL events had extended their horizontal range in the latitudinal direction by about $500 \mathrm{~km}$ at least. But the peak sodium 
densities and the peak velocities for the same event were different from each other; this may be the result of the local middle atmospheric dynamics (Note that there were greater differences for peak altitude and width on 6 January 2007, the contour plots for the two locations showed that SSL had been broadened at Hefei during its maximum period. We considered that this can also be explained by the local dynamical process). Still, there were two events that were not observed simultaneously, i.e., event from 22:24-23:26 LT on 2 November 2007 (as shown in Fig. 6), and event from 04:1304:52 LT on 14 December 2006 (as shown in Table 4). Owing to the lack of a third observational lidar, it cannot be determined from our two-point observation, whether these two events were very local phenomena.

To summarize, we did a comprehensive statistical analysis of SSL events using nearly three years of sodium density observations by the USTC lidar. The results are in agreement with those reported by previous studies at mid-latitude. With the help of ionosonde data, a considerable correlation with Pearson correlation coefficient 0.66 between seasonal variations of occurrence of SSL and those of Es during nighttime can be obtained, which was in line with the research made by Nagasawa and Abo (1995). From a comparison between the observations of the USTC lidar and the WIPM lidar, the least horizontal range for some events was estimated to be over $500 \mathrm{~km}$. We consider that more co-observations will greatly help us understand the horizontal ranges of SSL, and more comprehensive results can be obtained with the support of China Median Project (a national scientific project funded by the Ministry of Science and Technology of China. It is a comprehensive ground-based system to monitor space environment variations occurring in the middle-to-upper atmosphere, the ionosphere, etc., based on many instruments and a network of facilities, along a $120^{\circ} \mathrm{E}$ meridian chain, from Mohe, the northernmost station in China, and extending to the China Zhongshan station in the Antarctic; and a $30^{\circ} \mathrm{N}$ latitudinal chain, from the easternmost point at Shanghai to the western Lhasa station) which is under construction.

Acknowledgements. We thank the Yamagawa Observatory for their $f_{0} E_{S}$ data, and the Wuhan Institute of Physics and Mathematics (CAS) for their sodium layer observation data used in this paper. We also wish to thank referees for suggesting a number of substantial improvements in the manuscript. This work is supported by the grant of the Creative Program (kzcx2-yw-123) and the grant of the President Scholarship of Chinese Academy of Sciences, the National Natural Science Foundation of China (40804035, 40674087,40890165), Program for New Century Excellent Talents in University (NCET-08-0523), the China Meteorological Administration Grant (GYHY200706013), and the Innovation Program of the Chinese Academy of Sciences (IAP07307).

Topical Editor C. Jacobi thanks B. P. Williams and another anonymous referee for their help in evaluating this paper.

\section{References}

Batista, P., Clemesha, B., Batista, I., and Simonich, D.: Characteristics of the sporadic sodium layers observed at $23^{\circ} \mathrm{S}$, J. Geophys. Res., 94, 15349-15358, 1989.

Batista, P. P., Clemesha, B. R., and Simonich, D. M.: Horizontal structures in sporadic sodium layers at $23^{\circ} \mathrm{S}$, Geophys. Res. Lett., 18, 1027-1030, 1991.

Bills, R. E. and Gardner, C. S.: Lidar observations of the mesopause region temperature structure at Urbana, J. Geophys. Res., 98, 1011-1021, 1993.

Bills, R. E., Gardner, C. S., and Franke, S. J.: Na Doppler/temperature lidar: Initial mesopause region observations and comparison with the Urbana medium frequency radar, J. Geophys. Res., 96, 22701-22707, 1991.

Bowman, M. R., Gibson, A. J., and Sandford, M. C. W.: Observation of mesospheric $\mathrm{Na}$ atoms by tuner laser radar, Nature, 221, 456-458, 1969.

Chen, T., Xue, X., and Dou, X.: Lidar studies of nighttime sodium layer over Hefei, China, J. Univ. of Sci. \& Tech. of China, 37, 873-878, 2007.

Clemesha, B.: Sporadic neutral metal layers in the mesosphere and lower thermosphere., J. Atmos. Solar-Terres. Phys., 57, 725-736, 1995.

Clemesha, B., Kirchhoff, V., Simonich, D., and Takahashi, H.: Evidence of an extraterrestrial source for the mesospheric sodium layer., Geophys. Res. Lett., 5, 873-876, 1978.

Clemesha, B., Kirchhoff, V., Simonich, D., Takahashi, H., and Batista, P.: Spaced lidar and nightglow observations of an atmospheric sodium enhancement., J. Geophys. Res., 85, 3480-3484, 1980.

Clemesha, B., Simonich, D., Batistu, P., and Batista, I.: Lidar observation of atmospheric sodium at an equatorial location., J. Atmos. Solar-Terr. Phys., 60, 1773-1778, 1998.

Clemesha, B., Batista, P. P., Simonich, D. M., and Batista, I. S.: Sporadic structures in the atmospheric sodium layer, J. Geophys. Res., 109, D11306, doi:10.1029/2003JD004496, 2004.

Collins, S. C., Plane, J. M. C., Kelley, M. C., Wright, T. G., Soldan, P., Kane, T. J., Gerrard, A. J., Grime, B. W., Rollason, R. J., Friedman, J. S., Gonzalez, S. A., Zhou, Q. H., Sulzer, M. P., and Tepley, C. A.: A study of the role of ion-molecule chemistry in the formation of sporadic sodium layers, J. Atmos. Sol.-Terr. Phys., 64, 845-860, 2002.

Cox, R. and Plane, J.: An ion-molecule mechanism for the formation of neutral sporadic Na layers., J. Geophys. Res., 103, 63496359, 1998.

Cox, R. M., Self, D. E., and Plane, J. M. C.: A study of the reaction between $\mathrm{NaHCO} 3$ and $\mathrm{H}$ : Apparent closure on the chemistry of mesospheric Na, J. Geophys. Res., 106, 1733-1739, 2001.

Fan, Z. Y., Plane, J. M. C., and Gumbel, J.: On the global distribution of sporadic sodium layers, Geophys. Res. Lett., 34, L15808, doi:10.1029/2007GL030542, 2007.

Gardner, C., Kane, T., Senft, D., Qian, J., and Papen, G.: Simultaneous observations of sporadic $\mathrm{E}, \mathrm{Na}, \mathrm{Fe}$, and $\mathrm{Ca}$ + layers at Urbana, Illinois: three case studies., J. Geophys. Res., 98, 16865-16874, 1993.

Gardner, C. S. and Shelton, J. D.: Density response of neutral atmospheric layers to gravity wave perturbations, J. Geophys. Res., 90, 1745-1754, 1985.

Gardner, C. S. and Voelz, D. G.: Lidar studies of the nighttime 
sodium layer over Urbana, Illinois : 2. Gravity waves, J. Geophys. Res., 92, 4673-4694, 1987.

Gardner, C. S., Plane, J. M. C., Pan, W., Vondra, T., Murray, B. J., and Chu, X.: Seasonal variations of the $\mathrm{Na}$ and Fe layers at the South Pole and their implications for the chemistry and general circulation of the polar mesosphere, J. Geophys. Res., 110, D10302, doi:10.1029/2004JD005670., 2005.

Gibson, A. J. and Sandford, C.: The seasonal variation of the nighttime sodium layer, J. Atmos. Terr. Phys., 33, 1675-1684, 1971.

Gong, S., Yang, G., Wang, J., Liu, B., Cheng, X. W., Xu, J. Y., and Wan, W.: Occurrence and characteristics of sporadic sodium layer observed by lidar at a mid-latitude location, J. Atmos. Solar-Terr. Phys., 64, 1957-1966, 2002.

Hansen, G. and von Zahn, U.: Sudden sodium layers in polar latitudes, J. Atmos. Terr. Phys., 52, 585-608, 1990.

Heinrich, D., Nesse, H., Blum, U., Acott, P., Williams, B., and Hoppe, U.-P.: Summer sudden Na number density enhancements measured with the ALOMAR Weber Na Lidar, Ann. Geophys., 26, 1057-1069, 2008, http://www.ann-geophys.net/26/1057/2008/.

Hickey, M. P. and Plane, J. M. C.: A chemical-dynamical model of wavedriven sodium fluctuations, Geophys. Res. Lett., 22, 28612864, 1995.

Kane, T., Grime, B., Franke, S., Kudeki, E., Urbina, J., Kelley, M., and Collins, S.: Joint observations of sodium enhancements and field aligned ionospheric irregularities., Geophys. Res. Lett., 28, 1375-1378, 2001.

Kane, T. J., Hostetler, C. A., and Gardner, C. S.: Horizontal and vertical structure of the major sporadic sodium layer events observed during ALOHA-90, Geophys. Res. Lett., 18, 1365-1368, 1991.

Kwon, K., Senft, D., and Gardner, C.: Lidar observations of sporadic sodium layers at Mauna Kea Observatory, Hawaii, J. Geophys. Res., 93, 14199-14208, 1988.

Kwon, K. H., Gardner, C. S., and Senft, D. C.: Daytime lidar measurements of tidal winds in the mesospheric sodium layer at Urbana, Illinois, J. Geophys. Res., 92, 8781-8786, 1987.

Mathews, I., Zhou, Q., Philbrich, C., Morton, Y., and Gardner, C.: Observations of ion and sodium layer coupled processes during AIDA., J. Atmos. Terr. Phys., 55, 487-498, 1993.

Megie, M. and Blamont, J. E.: Laser sounding of atmospheric sodium interpretation in terms of global atmospheric parameters, Planet. Space Sci., 25, 1093-1109, 1977.

Nagasawa, C. and Abo, M.: Lidar observations of a lot of sporadic sodium layers in mid-latitude., Geophys. Res. Lett., 22, 263-266, 1995.

Nesse, H., Heinrich, D., Williams, B., Hoppe, U.-P., Stadsnes, J., Rietveld, M., Singer, W., Blum, U., Sandanger, M. I., and Trondsen, E.: A case study of a sporadic sodium layer observed by the ALOMAR Weber Na lidar, Ann. Geophys., 26, 1071-1081, 2008, http://www.ann-geophys.net/26/1071/2008/.

Papen, G. C., Pfenninger, W. M., and Simonich, D. M.: Sensitivity analysis of $\mathrm{Na}$ narrowband wind-temperature lidar systems, Appl. Optics, 34, 480-498, 1995.

Plane, J. M., Gardner, C. S., Yu, J., She, C. Y., Garcia, R. R., and Pumphrey, H. C.: Mesospheric Na layer at 40N: Modeling and observations., J. Geophys. Res., 104, 3773-3788, 1999.

Vishnu Prasanth, P., Sridharan, S., Bhavani Kumar, Y., and Narayana Rao, D.: Lidar observations of sporadic Na layers over
Gadanki $\left(13.5^{\circ} \mathrm{N}, 79.2^{\circ} \mathrm{E}\right)$, Ann. Geophys., 25, 1759-1766, 2007, http://www.ann-geophys.net/25/1759/2007/.

Qian, J., Gu, Y., and Gardner, C.: Characteristics of the sporadic $\mathrm{Na}$ layer observed during the Airborne Lidar and Observations of Hawaiian Airglow/Airborne Noctilucent cloud (ALOHA/ANLC-93) campaigns., J. Geophys. Res., 103, 63336347, 1998.

Senft, D., Collins, R., and Gardner, C.: Mid-latitude lidar observations of large sporadic sodium layers., Geophys. Res. Lett., 16, 715-718, 1989.

She, C. Y., Yu, J. R., Latifi, H., and Bills, R. E.: High-spectralresolution fluorescence light detection and ranging for mesospheric sodium temperature measurements, Appl. Optics, 31, 2095-2106, 1992.

She, C. Y., Chen, S. S., Hu, Z. L., Sherman, J., Vance, J. D., Vasoli, V., White, M. A., Yu, J. R., and Krueger, D. A.: Eight-year climatology of nocturnal temperature and sodium density in the mesopause region (80 to $105 \mathrm{~km}$ ) over Fort Collins, CO (41 N, 105 W), Geophys. Res. Lett., 27, 3289-3292, 2000.

Simonich, D. M., Clemesha, B. R., and Kirchhoff, V. W. J. H.: The mesospheric sodium layer at $23 \mathrm{~S}$ : Nocturnal and seasonal variations., J. Geophys. Res., 84, 1543-1550, 1979.

States, R. J. and Gardner, C. S.: Structure of the mesospheric Na layer at $40^{\circ} \mathrm{N}$ latitude: Seasonal and diurnal variations, J. Geophys. Res., 104, 11783-11798, 1999.

Swider, W.: Mesospheric sodium: Implications using a steady-state model, Planet. Space Sci., 34, 603-608, 1986.

Von Zahn, U. and Hansen, T.: Sudden neutral sodium layers: a strong link to sporadic E layers., J. Atmos. Terr. Phys., 50, 93104, 1988.

von Zahn, U., von der Gathen, P., and Hansen, G.: Forced release of sodium from upper atmospheric dust particles, Geophys. Res. Lett., 14, 76-79, 1987.

Williams, B. P., Croskey, C. L., She, C. Y., Mitchell, J. D., and Goldberg, R. A.: Sporadic sodium and E layers observed during the summer 2002 MaCWAVE/MIDAS rocket campaign, Ann. Geophys., 24, 1257-1266, 2006, http://www.ann-geophys.net/24/1257/2006/.

Williams, B. P., Berkey, F. T., Sherman, J., and She, C. Y.: Coincident extremely large sporadic sodium and sporadic E layers observed in the lower thermosphere over Colorado and Utah, Ann. Geophys., 25, 3-8, 2007, http://www.ann-geophys.net/25/3/2007/.

$\mathrm{Xu}$, J. and Smith, A. K.: Perturbations of the sodium layer: controlled by chemistry or dynamics?, Geophys. Res. Lett., 30(20), 2056, doi:10.1029/2003GL018040, 2003.

Yi, F., Zhang, S., Yu, C., He, Y., Yue, X., Huang, C., and Zhou, J.: Lidar observations of sporadic $\mathrm{Na}$ layers over Wuhan (30.5 N, 114.4 E), Geophys. Res. Lett., 29(9), 1345, doi:10.1029/2001GL014 353, 2002.

Yi, F., Zhang, S., Yu, C., He, Y., Yue, X., Huang, C., and Zhou, J.: Simultaneous observations of sporadic Fe and Na layers by two closely colocated resonance fluorescence lidars at Wuhan (30.5 N, 114.4 E), China, J. Geophys. Res., 112, D04303, doi:10.1029/2006JD007413, 2007.

Yi, F., Yu, C., Zhang, S., Yue, X., He, Y., Huang, C., Zhang, Y., and Huang, K.: Seasonal variations of the nocturnal mesospheric $\mathrm{Na}$ and Fe layers at $30^{\circ} \mathrm{N}$, J. Geophys. Res., 114, D01301, doi:10.1029/2008JD010344, 2009. 